\title{
DIRETIVAS ANTECIPADAS DE VONTADE: AVANÇOS, RETROCESSOS E POSSIBILIDADES DA AUTONOMIA VOLITIVA NO DIREITO BRASILEIRO
}

\author{
Breno Silveira Moura Alfeu*1 \\ Fernanda Leontsinis Carvalho Branco ${ }^{* 2}$
}

\section{RESUMO}

O presente trabalho tem como objetivo responder o seguinte questionamento: quais as possibilidades das Diretivas Antecipadas de Vontade no direito brasileiro? Para tanto, o estudo aborda, sequencialmente, a configuração teórica do instituto, sua adequação com o direito civil brasileiro, sua situação atual no plano jurídico do País e os avanços obtidos, óbices e retrocessos. Assim, será possível tecer delimitação e verificar compatibilidade desse instituto na realidade do Direito brasileiro. Com isso em foco, elaborou-se a presente pesquisa qualitativa básica que se vale de abordagens hipotético-descritivas e dedutivas, bem como foi desenvolvida baseada fontes bibliográficas e documentais conferidas diretamente.

Palavras-chave: Autonomia da Vontade; Diretivas Antecipadas de Vontade; Direito Civil; Delimitação; Possibilidades.

\section{ANTECIPATED DIRECTIVES: ADVANCES, RETREATS AND POSSIBILITIES OF THE AUTONOMY OF WILL IN BRAZILIAN LAW}

\begin{abstract}
This paper aims to answer the following question: what are the possibilities of the Antecipated Directives in Brazilian law? To accomplish this, the study addresses, sequentially, the theoretical configuration of the institute, its adequacy with brazilian Civil Law, its current situation in the country's legal panorama and the advances obtained, obstacles and setbacks. Thus, it will be possible to delimit and verify the compatibility of this institute in the reality of Brazilian law. To this end, this basic qualitative research was elaborated, using hypothetical-descriptive and deductive approaches, as well as being developed based on bibliographic and documentary sources directly conferred.
\end{abstract}

Keywords: Autonomy of Will; Antecipated Directives of Will; Civil law; Delimitation; Possibilities.

\footnotetext{
${ }^{1}$ Mestre em Direito pela Universidade Federal do Ceará - UFC (2021), na área de concentração: Constituição, Sociedade e Pensamento Jurídico. Especialista em Direito Digital e Compliance pela instituição Universidade Damásio Educacional (2020). Graduado em Direito pela Universidade Federal do Ceará - UFC (2017). Advogado atuante nas áreas de Direito Civil, Direito Bancário, Direito Digital e Direito do Consumidor. Tem experiência acadêmica em Direito, pesquisando, principalmente, nos seguintes temas: Direito Constitucional, Direito Civil, Ensino Jurídico, Responsabilidade Civil, Direito Bancário, Direito do Consumidor e Direito Digital. Currículo lattes: http://lattes.cnpq.br/1890051313997152. E-mail: Brenosma@hotmail.com.

${ }^{2}$ Mestra em Direito pela Universidade Federal do Ceará - UFC (2021), na área de concentração: Constituição, Sociedade e Pensamento Jurídico. Graduada em Direito pela Universidade Federal do Ceará - UFC (2017). Advogada e residente jurídica, atuando junto ao Tribunal de Justiça do Estado do Ceará. Tem experiência acadêmica em Direito, pesquisando, principalmente, nos seguintes temas: Direito Constitucional, Direito Penal, Direito Civil, Bioética, Direito e Arte e Direito e Literatura. Currículo lattes: http://lattes.cnpq.br/1196578329003376. E-mail: feleontsinis@gmail.com.
} 


\section{INTRODUÇÃO}

A autonomia da vontade é elemento básico de constituição da ordem do Direito Civil brasileiro, compondo preceitos primários de estruturação dos institutos desse âmbito. De fato, desde observações mínimas da capacidade civil até construtos mais complexos como a teoria dos negócios jurídicos, é inevitável a constatação da vontade como fundamento da seara civilista.

Em função dessa centralidade, há influência dela nas mais diversas configurações fáticas da vida em sociedade. É possível conceber, nesse contexto, problemática da autonomia volitiva em situações em que o indivíduo está impossibilitado de externá-la. Essa ocorrência pode representar um óbice para a eficácia das normas de direito afetas a esse elemento básico, uma vez que a comunicação ou conhecimento da vontade individual é condição de possibilidade para isso.

Todavia, há resposta a essa problemática para situações concernentes ao Direito à Vida, à Dignidade Humana e à personalidade da pessoa. Ela corresponde às Diretivas Antecipadas de Vontade (DAV), as quais constituem instituto de expressão da vontade, preservando a autonomia individual exatamente para casos em que, usualmente, ela seria cerceada ou ignorada. Assim, objetiva-se efetivar, por meio delas, respeito aos desígnios da pessoa, vinculando terceiros a estipulações prévias do próprio particular.

Nessa perspectiva, surge o seguinte questionamento: quais as possibilidades das Diretivas Antecipadas de Vontade no direito brasileiro?

O escopo do presente trabalho é analisar o referido instituto de proteção à autonomia volitiva na realidade jurídica brasileira, verificando-se como se encontra na atualidade, bem como os avanços e retrocessos ocorridos na sua configuração junto ao direito do País. O fito colimado pela presente pesquisa não é apenas a demonstração da temática, mas discussão dela, perpassando o seu desenvolvimento no sistema de direito brasileiro, destacando as principais ocorrências de avanços e de retrocessos do assunto. A partir disso, será possível explicitar suas possibilidades na delimitação contextual e espacial referida.

Este estudo se mostra necessário em razão da centralidade da autonomia volitiva em um cenário de maiores contenções e conformações na ordem jurídica nacional, que se 
caracteriza não mais pela irrestrição individual e sim pelo exercício dos desígnios particulares sob parâmetros de sociabilidade e alteridade.

Justifica-se, assim, a produção normativa no sentido de proteger da vontade individual como expressão do Direito à Vida e da Dignidade Humana, projetando-a de forma a salvaguardar a própria pessoa quando ela não puder se comunicar com terceiros. E, então, evitando, por consequência, sua submissão completa a decisões e compreensões de outrem. Em mesma medida, é justificada a análise desse tema, porque, com isso, é possível não apenas disseminar sua compreensão, mas agregar ao seu aprofundamento teórico, permitindo melhor percepção das suas possibilidades de eficácia na casuística contemporânea.

O presente trabalho foi desenvolvido em cinco partes. Introdução que é a presente e que trata de apresentação preliminar da temática (objeto de análise), bem como do questionamento, do escopo, da relevância e da justificativa para a sua realização, além do planejamento metodológico.

Primeira seção que corresponde à verificação de premissas básicas da temática e sua compreensão a partir do Direito Civil do Brasil. Isto porque ela consubstancia um negócio jurídico de cunho existencial. A segunda seção é correspondente à observação das Diretivas Antecipadas de Vontade na ordem jurídica, enfocando dois expoentes que representam avanço dela na realidade nacional. A terceira seção aborda o retrocesso e o óbice ao desenvolvimento das DAV no País, mediante apreciação dos pontos de enfoque anteriores, contribuindo para uma orientação acerca da delimitação da estrutura teórica e normativa necessárias ao assunto para produção e eficiência no ambiente a que ele se propõe. A última parte trata das considerações finais, a qual é constituída por sintetização e compatibilização das conclusões, questões e constatações realizadas no decorrer do presente trabalho.

Assim, este trabalho científico se trata de uma pesquisa qualitativa básica que se vale de abordagens hipotético-descritivas e dedutivas, bem como foi desenvolvida mediante em fontes bibliográficas e documentais conferidas diretamente.

\section{CONFIGURAÇÃO TEÓRICA DAS DIRETIVAS ANTECIPADAS DE VONTADE}

A configuração teórica das Diretivas Antecipadas de Vontade tem como premissa fundamental a dignidade humana, do que decorre a autonomia da vontade e o respeito aos desígnios individuais como normas éticas, inclusive na seara médica (NUNES, 2016, p. 13,17, 22, 42). Ou seja, a referida premissa origina um dever de proteção ao indivíduo. 
Não sendo raras as situações em que são obstadas a informação das escolhas e a formação das decisões da própria pessoa para consigo, o instituto referido foi concebido, no sistema jurídico norte-americano, como resposta de efetivação daquela proteção, originando diversas formas de viabilizar esse fito específico.

Diretivas Antecipadas de Vontade são o gênero de uma classificação ampla de modalidades de manifestações prévias de vontade acerca de tratamentos médicos para situações em que o elemento volitivo não seja possível de ser externado (DADALTO; TUPINAMBÁS; BARTOLOMEU, 2013, p. 464). Essa classificação resulta da unificação conceitual a partir de uma revisão bibliográfica da temática realizada por Amy E. Thompson (2015, p. 868), a qual verificou diversas percepções teóricas, documentais e normativas que em comum permitiam delinear uma categoria mais ampla, que é a mencionada.

Esse gênero é subdividido em outras duas categorias: o testamento vital, que detém como denominação original o termo living will; e o mandato duradouro, denominado durable power of attorney for health care (DPAHC).

O testamento vital surgiu nos Estados Unidos da América, em 1969, a partir de proposição concebida por Luis Kutner (1969). Sua concepção inicial é relativa ao documento de veiculação da vontade de paciente médico - civilmente capaz - que, ainda dotado de completas faculdades mentais, determina - previamente - até que limite ele concorda se submeter a tratamento médico, quando estiver em estado vegetativo ou não puder recobras suas capacidades físicas e mentais (KUTNER, 1969, p. 551-552).

Nessa concepção inicial, o living will não direciona a conduta médica para encerramento ativo da vida do paciente, mas apenas para cessar os atos que posterguem um quadro clínico irreversível (KUTNER, 1969, p. 550, 552-554). Isso evidencia que o referido instituto origina modalidade de informação da vontade que não se coaduna com a eutanásia ${ }^{3}$, mas sim com práticas de ortotanásia ${ }^{4}$.

Posteriormente, o instituto foi modificado ao ser transplantado ou quando está previsto em sistemas jurídicos que permitem práticas de morte por piedade, seja de forma

\footnotetext{
${ }^{3}$ Vale ressaltar que o significado empregado no presente trabalho para eutanásia é de agir ativamente para findar vida ainda passível de manutenção e cuidados ou procedimentos proporcionais que possam restabelecer a sua saúde, sendo ativa quando uma ação terminar a função vital ou passiva quando uma omissão o fizer (LOPES; LIMA; SANTORO, 2014, p. 56-57).

${ }^{4}$ A ortotanásia corresponde à cessação de cuidados médicos extraordinários e desproporcionais para situações em que o encerramento da vida seja inevitável, modificando-se o foco da busca pela cura para a efetivação de qualidade de vida no tempo restante (LOPES; LIMA; SANTORO, 2014, p. 58).
} 
direta e explícita - como é o caso de Holanda, Luxemburgo e Bélgica -, seja de maneira indireta a partir de flexibilização doutrinária ou jurisprudencial, o que se observa no Japão, México, Canadá, Chile, Reino Unido e França (SILVA, 2007, p. 141-164).

Por sua vez, o mandato duradouro foi concebido, em 1983, na Califórnia, nos Estados Unidos da América, sendo ampliado a todo o território do referido país por meio da aprovação do Patient Self-Determination Act (SILVA, 2007, p. 87), que é a legislação federal daquela nação que reconhece o Direito à Autodeterminação do Paciente ${ }^{5}$.

Ele consiste na nomeação de terceiro para tomar as decisões relativas a tratamentos médicos quando o paciente estiver impossibilitado permanente ou temporariamente (DADALTO; TUPINAMBÁS; BARTOLOMEU, 2013, p. 464). Essa espécie constitui um modelo de julgamento substituto, o qual se estrutura pela suposição de que haja intimidade entre o nomeado e o paciente, de maneira que aquele possa decidir com base nos objetivos e desejos deste (BEAUCHAMP; CHILDRESS, 2011, p. 195). Desse modo, excluem-se das possibilidades de nomeação indivíduos desconhecidos pelo paciente. Com foco no atendimento dessa intimidade, que é um requisito, usualmente, nomeiam-se familiares ou amigos (MONTEIRO; JÚNIOR, 2019, p. 87).

Ambas as referidas espécies de Diretivas Antecipadas de Vontade podem coexistir, não havendo exclusão necessária, caso escolhida uma ou outra, dependendo apenas da vontade do paciente em constituí-las isolada ou conjuntamente (DADALTO, 2013b, p. 83). Desse modo, de acordo com a adaptação e com as circunstâncias que colimam corresponder, elas podem constituir modalidades mais específicas a depender das formas de externalização da vontade do paciente com maior ou menor precisão (ou detalhamento) e abstração (ou abrangência).

Além do exposto, nos Estados Unidos, há recorrentemente a criação de modalidades derivadas dessas duas espécies, as quais, sobretudo, exorbitam daquela compreensão básica eficácia do instituto vinculada a um contexto de terminalidade da vida (PENALVA, L. D., 2008, p. 516-538). Deve-se ressaltar, isto posto, que essas outras concepções fazem parte do gênero Diretivas Antecipadas de Vontades, pois o que fazem é ampliar o instituto trazendo a consideração de dispensabilidade da situação de fim das funções vitais. São exemplos dessas

\footnotetext{
${ }^{5}$ Necessário ressaltar que o Patient Self-Determination Act, por ser legislação federal em um país em que a autonomia dos estados-membros é a regra - somado ao fato de que 35 estados já tinham legislado sobre o tema -, é uma diretriz, mas que também serve para orientar soluções de conflitos éticos, além de servir como norma de informação pública acerca temática (PONA, 2015; EMANUEL; EMANUEL, 1990).
} 
novas formas de Diretivas: a Advance Medical Care Directive ${ }^{6}$; value history ${ }^{7}$; a Combine Directive $^{8}$; e o Physician Orders for Life-Sustaining Treatment (POLST) ${ }^{9}$.

O que se observa, ante o exposto, na configuração geral da teoria das Diretivas Antecipadas de Vontade, é o escopo comum de proteger a vontade individual mediante meios de comunicação dela a terceiros. E isso resulta na materialização de um documento ou de instrução específica.

É possível observar esse instituto sob duas vertentes, uma objetiva - que trata do contexto fático ao qual se aplicam as suas previsões normativas - e outra subjetiva, em relação aos declarantes. Objetivamente, ela é estruturada em um contexto de relação médico-paciente, buscando orientar a atuação do profissional de medicina em prol do respeito à autonomia volitiva e ao exercício conjunto do Direito à Vida e da Dignidade Humana. Subjetivamente, ela pode ocorrer ou por expressão do próprio titular isoladamente, por decisão tomada de maneira conjunta, ou por ato de terceiros. Há variação na forma em que o elemento volitivo é formado, o que evidencia diferenciação entre as espécies de diretivas.

Com base na teoria geral dos fatos e atos jurídicos, as Diretivas Antecipadas de Vontade são declarações volitivas que originam um negócio jurídico de cunho existencial ${ }^{10}$. A sua eficácia é da modalidade inter vivos, uma vez que as normas jurídicas cogentes de Direito Civil aplicam-se às questões posteriores e relativas à morte da pessoa. Elas também são negócios de caráter obrigacional eminente, uma vez que determinam e orientam padrões de conduta do médico, que é a contraparte da relação sobre a qual se realizam os seus efeitos.

É duvidosa a verificação acerca de seu modo de existência, uma vez que pode ser tanto um negócio principal quanto um acessório, posto que as circunstâncias concretas são o

\footnotetext{
${ }^{6}$ Documento que registra a vontade do paciente sobre tratamentos que deseja ou não a partir de discussão entre ele e a equipe de saúde que lhe atende (DADALTO, 2013a, p. 23). Ademais, esse documento pode incluir a previsão, adoção e indicação de mandato duradouro (PENALVA, 2008. p. 516-538).

${ }^{7}$ Documento em que o particular registra seus valores pessoais que direcionaram a tomada de decisão sobre seu tratamento médico (DADALTO, 2013a, p. 23).

${ }^{8}$ Documento que une instrução do paciente, nomeação de mandatário e os valores do indivíduo, sendo, portanto, uma sintetização geral das outras espécies (DADALTO, 2013a, p. 23).

9 Consiste em um formulário padronizado de ordens aos médicos baseadas nos valores e preferências do indivíduo acerca de tratamentos prolongadores de sua vida e que devem acompanhar o paciente no seu trânsito em qualquer local de atendimento de saúde (MAYORAL, 2016, p. 27 - 30).

${ }^{10} \mathrm{O}$ cunho existencial dos negócios jurídicos admite-se e se apresenta como tendência decorrente da despatrimonialização do Direito Civil, sendo esse paradigma contemporâneo, bem como é movimento que possibilitou o afastamento do núcleo patrimonial e da lógica do lucro adotadas na teoria clássica dos contratos (LIMA; SANTOS; MARQUESI, 2018, p. 11-13, 16-18, 22-23).
} 
que evidenciarão isso. Por exemplo, instituição das diretivas como requisito de um contrato de prestação de serviço médico, ou formação de uma diretiva para subordinar todo e qualquer serviço médico a ser prestado. Contudo, o regramento da localidade específica em que ele será previsto ou será formalizado determinará se será uma ou outra.

A depender da espécie de diretiva e da quantidade de partes declarantes para a sua constituição, esse ato de vontade pode se dar de forma unilateral, bilateral ou plurilateral. Igualmente, pode ser um ato simples, complexo ou coligado. Em relação à vantagem negociada, o cunho existencial elimina qualquer hipótese de cunho gratuito ou oneroso, motivo pelo qual se observa ser ele um negócio jurídico neutro, em que o benefício é de natureza imaterial consubstanciada no respeito ao desígnio do particular.

Por fim, conforme já explicitado para o modo de existência, a necessidade de as Diretivas Antecipadas de Vontade serem atos negociais formais ou informais depende do sistema jurídico sob o qual ela está sendo formada. E isso porque não há características específicas na configuração teórica, como se perquiriu, acerca disso.

O que se observou é que, normalmente, elas detêm forma escrita. Porém, essa obrigatoriedade não se encontra plasmada invariavelmente nas espécies perquiridas, sendo possível admitir que qualquer meio apto a registrar e transmitir a vontade pode ser próprio para a sua constituição. No entanto, essa liberdade de formas que, usualmente, é regra nos sistemas jurídicos de natureza privada, ou civilista, pode ser mitigada, como já o é para algumas modalidades negociais, a exemplo do que se vê das previsões dos artigos 108 e 109 do Código Civil de nosso País.

Expostos os elementos da estruturação básica das Diretivas Antecipadas de Vontade, devem serem abordados o estado em que se encontra dessa temática dentro do panorama jurídico brasileiro, bem como o estágio de desenvolvimento dela no País.

\section{ATUALIDADE E AVANÇOS DAS DIRETIVAS NO BRASIL}

No Brasil, as Diretivas Antecipadas de Vontade se fazem presentes na realidade jurídica de forma excepcional. É que o tratamento dispensado à matéria para além de um marco teórico ainda não ocorreu de forma legislativa.

Atualmente, as previsões normativas relativas a elas são, primária e inicialmente, de ordem administrativa, havendo também enfrentamento judicial sobre a temática, que ocorreu por consequência àquela primeira. 
Ao contrário do que se espera para uma cultura jurídica baseada no texto legislativo como fonte primária de normas de Direito, o mencionado instituto é exceção a essa ocorrência regular do direito brasileiro. O Conselho Federal de Medicina do Brasil (CFM) foi a primeira entidade pública a apresentar vetores normativos tocantes às Diretivas. Isso ocorreu mediante a publicação da Resolução nº 1.995 , de 31 de agosto de 2012.

Essa norma daquele ente de classe colmatou, em alguma medida, o vazio legislativo existente para as situações em que a vontade individual não pudesse ser transmitida pelo seu titular. Porém, ela foi restrita a contextos de médicos atinentes a situações de terminalidade vital, delimitando o poder de atuação do profissional de medicina de acordo com o que entender o paciente. E isso é o que se observa da integralidade daquela resolução, com vistas não apenas a seus artigos.

Com efeito, os consideranda do regramento referido demonstram diversos pressupostos para a base teórica das Diretivas Antecipadas no Brasil. O primeiro deles é a relevância da autonomia individual na relação médico-paciente. Ao lado de explicitar o contexto específico ao qual é aplicado o conjunto normativo previsto naquela norma regulamentadora, isso detém especial relevância, já que a conduta ética-médica hodierna é pautada em um vínculo de confiança (MABTUM; MARCHETTO, 2015, p. 73).

Este se concretiza e resulta no respeito mútuo entre seus partícipes, com enfoque principal na personalidade do indivíduo enfermo (NUNES, 2016, p. 42). Como forma de reforçar esse paradigma, o Código de Ética Médica determina que a atuação do profissional de medicina não pode ir de encontro ao respeito à dignidade e integridade humanas, bem como ao consentimento livre do paciente sob quais procedimentos ele deseja receber, inclusive em situações de terminalidade vital ${ }^{11}$. Não respeitando essas normas deontológicas, o médico será sujeito a penalidades administrativas e jurídicas. Por exemplo, indenização por danos morais (NUNES, 2016, p. 67).

O segundo pressuposto para incidência das previsões normativas das diretivas é haver situação de terminalidade vital. É necessário destacar que essa situação não é uma ocorrência simples, mas sim sua ocorrência em um contexto tecnológico da atualidade, em que é possível prolongar as funções vitais do enfermo, mesmo contra sua vontade - inclusive, por desconhecimento do real desígnio do indivíduo -, sacrificando a qualidade de vida dele

\footnotetext{
${ }^{11}$ Artigos $1^{\circ}$, IV, 22, 31 e 41, parágrafo único, do Código de Ética Médica: Resolução CFM no 2.217, de 27 de setembro de 2018, modificada pelas Resoluções CFM n ${ }^{0}$ 2.222/2018 e 2.226/2019.
} 
em prol de parâmetros quantitativos e não qualitativos ${ }^{12}$. Outrossim, as normas deontológicas médicas vedam essa conduta, expressamente ${ }^{13}$.

O terceiro pressuposto é a ausência de regramento no âmbito administrativo sobre a temática, não havendo marco geral, específico e seguro para que o médico ou o paciente pudesse guiar sua atuação ao se deparar com situação enquadrada no assunto ora analisado. Tal situação ocasionaria receio do profissional na escolha dos meios e práticas a serem empregadas, de modo que ele escolheria aquela que lhe parecesse menos gravosa a si, em detrimento da vontade do seu paciente.

O Conselho Federal de Medicina aferiu, em razão disso, a necessidade de disciplinar a temática, editando a Resolução 1.995/2012, fazendo uso de sua prerrogativa de produção normativa deontológica e poder fiscalizatório para a efetivação de suas regras (PITELLI, 2002, p. 55). E esse é o quarto pressuposto para a temática no Brasil.

Por fim, o quinto pressuposto, que é o último deles, corresponde à falta de legislação específica sobre as Diretivas Antecipadas de Vontade, motivo pelo qual a anomia existente poderia resultar em restrição, no plano fático do cotidiano, ao exercício de direitos, embora seja isso inconcebível no paradigma jurídico atual de vieses concretistas da jurisdição constitucional (MENDES, 1999, p. 308; GRAU, 1995, p. 46). E isso resulta em não poder haver assentimento do Poder Público com a inércia legislativa por ser imperativo jurídico a concretização de direitos previstos constitucional ou infraconstitucionalmente.

Além disso, é vedada inércia de efetivação de direitos sob a justificativa da ausência de norma específica no âmbito do Poder Judiciário, especialmente quando isso decorre do exercício de prerrogativas básicas do ser humano, que são o Direito à Vida, Dignidade Humana e Autonomia da Vontade (CAIXETA, 2016, p. 84-89).

Ao lado desses pressupostos demonstrados nos consideranda da resolução investigada, há justificativas para a edição de regulamentação administrativa sobre a temática. A primeira delas necessidade de facilitação da comunicação de pacientes em situação de terminalidade, sendo essa a razão de necessidade de registro e respeito à sua vontade previamente manifestada (CONSELHO FEDERAL DE MEDICINA, 2012, p. 3).

\footnotetext{
${ }^{12}$ Prática também conhecida como distanásia, ou obstinação terapêutica (LOPES; LIMA; SANTORO, 2014, p. 61).

${ }^{13}$ Artigos 41 e 57 do Código de Ética Médica: Resolução CFM no 2.217, de 27 de setembro de 2018, modificada pelas Resoluções CFM n ${ }^{0}$ 2.222/2018 e 2.226/2019.
} 
Em segunda justificativa, há a receptividade dos médicos às diretivas antecipadas, pois, em pesquisas nacionais e internacionais, os profissionais dessa seara se demonstram mais tranquilos e seguros ao receber orientação para sua conduta por aquele de que cuidam ${ }^{14}$. A terceira justificativa decorre, simetricamente à anterior, da receptividade dos pacientes quanto às diretivas, posto que eles entendem necessário o atendimento e respeito ao que compreendem como compatível com sua personalidade ${ }^{15}$.

A quarta delas se observa na existência de padrões internacionais sobre a temática, aos quais o Conselho Federal de Medicina busca alcançar. Com efeito, os códigos de ética médica da Itália (em seu artigo 34), da Espanha (em seu artigo 27) e de Portugal (artigo 46) tratam a temática. A quinta justificativa se relaciona com o fato de que as problemáticas afetas a conflitos morais no campo ético deveriam ser tratados por um Comitê de Bioética, os quais são escassos em quantidade, o que recai ao próprio órgão de classe a necessidade de regulamentação da matéria (CONSELHO FEDERAL DE MEDICINA, 2012, p. 4).

A partir de todos esses pressupostos e justificativas, é que se origina a regulamentação mediantes três artigos, os quais seguem:

Art. $1^{\circ}$ Definir diretivas antecipadas de vontade como o conjunto de desejos, prévia e expressamente manifestados pelo paciente, sobre cuidados e tratamentos que quer, ou não, receber no momento em que estiver incapacitado de expressar, livre e autonomamente, sua vontade.

Art. $2^{\circ}$ Nas decisões sobre cuidados e tratamentos de pacientes que se encontram incapazes de comunicar - se, ou de expressar de maneira livre e independente suas vontades, o médico levará em consideração suas diretivas antecipadas de vontade.

$\S 1^{\circ}$ Caso o paciente tenha designado um representante para tal fim, suas informações serão levadas em consideração pelo médico.

$\S 2^{\circ} \mathrm{O}$ médico deixará de levar em consideração as diretivas antecipadas de vontade do paciente ou representante que, em sua análise, estiverem em desacordo com os preceitos ditados pelo Código de Ética Médica.

\footnotetext{
${ }^{14} \mathrm{Na}$ Espanha, levantamento estatístico junto à classe médica demonstrou que 90\% deles atenderiam à vontade antecipadamente registrada pelo paciente, caso houvesse registro disso para situações de impossibilidade de comunicação junto a este (SIMÓN-LORDA; TAMAYO-VELÁZQUEZ; BARRIO-CANTALEJO, 2008). No Brasil, quando questionados sobre a temática, médicos, advogados e estudantes de medicina ou direito, no total de 209 pessoas, 60,8\% deles afirmaram preferir as diretivas, apesar de ser disponível a administração de práticas terapêuticas de ortotanásia para pacientes em fase terminal de vida (PICCINI et al, 2011).

${ }^{15} \mathrm{Na}$ Europa, $75 \%$ dos pacientes em tratamento médico desejam que sejam realizadas consigo discussões sobre isso, apesar da possibilidade de não saberem precisar, com toda certeza, o que desejariam no futuro nessas situações (SAHM; WILL; HOMMEL, 2005). Nos Estados Unidos da América, há constatação estatística de que, em situação de moléstia severa ou impossibilidade de tomar a decisão, $47 \%$ dos pacientes desejam realizar as diretivas para orientar a atuação médica, $27 \%$ nomeariam um substituto nas suas diretivas para tomar as decisões cabíveis, $22 \%$ preferem que as famílias decidam por si e $4 \%$ preferem que os médicos tomem a decisão (JOHN; HEFFNER; BARBIERI, 2000).
} 
$\S 3^{\circ}$ As diretivas antecipadas do paciente prevalecerão sobre qualquer outro parecer não médico, inclusive sobre os desejos dos familiares.

$\S 4^{\circ} \mathrm{O}$ médico registrará, no prontuário, as diretivas antecipadas de vontade que lhes foram diretamente comunicadas pelo paciente.

$\S 5^{\circ}$ Não sendo conhecidas as diretivas antecipadas de vontade do paciente, nem havendo representante designado, familiares disponíveis ou falta de consenso entre estes, o médico recorrerá ao Comitê de Bioética da instituição, caso exista, ou, na falta deste, à Comissão de Ética Médica do hospital ou ao Conselho Regional e Federal de Medicina para fundamentar sua decisão sobre conflitos éticos, quando entender esta medida necessária e conveniente.

Art. $3^{\circ}$ Esta resolução entra em vigor na data de sua publicação.

O que se observa das normas editadas são sua compatibilidade com a expansão da vontade individual que se faz central no Direito Civil, posto que o efetivo tratamento do tema é realizado pelos dois primeiros artigos, já que o terceiro apenas cuida do vigor e da vigência normativa. O primeiro deles traz definição que deve ser observada em conjunto com as questões já estudadas e que estão presentes nessa mesma norma de regência.

De fato, somente o artigo $2^{\circ}$ trata de questões de regramento específico. E dele se observa compatibilidade com vetores principiológicos atinentes à teoria dos negócios jurídicos, bem como ao que disciplina o Código Civil brasileiro. Com efeito, no País, os atos da vida civil que se caracterizam e são estruturados a partir da expansão da vontade individual detêm - como corolário reconhecidamente legal - a liberdade de formas. Essa constatação é evidenciada pelos artigos 104, inciso III, e 107 do aludido Código Civil.

Evidente que está, assim, consolidada a prevalência da vontade individual e o prestígio aos desígnios do enfermo no contexto da relação médico-paciente. $\mathrm{E}$ isso foi feito em conformidade com a legislação. Esse foi o tratamento inicial das Diretivas Antecipadas de Vontade na realidade jurídica brasileira.

Posteriormente, em função do enfrentamento de vácuo normativo existente sobre a temática, a adequação da Resolução no 1.995/2012 foi questionada junto ao Judiciário. E isso marca um segundo momento de tratamento da questão pela ordem jurídica nacional, bem como o processo que consubstanciou essa discussão representou marco da temática, sendo destaque para o aprofundamento da discussão, trazendo, inclusive, novas perspectivas sobre a normatização da temática.

Em 2013, foi proposta a Ação Civil Pública de nº 0001039-86.2013.4.01.3500, ajuizada pelo Ministério Público Federal em face do Conselho Federal de Medicina (CFM), tendo como objeto a impugnação da resolução sobredita sob o argumento de que ela se 
encontra contrária à ordem jurídica do País em variados aspectos. Durante o desenvolver da referida ação - a qual ainda não se findou, mas se encontra em análise da segunda instância da Justiça Federal da Primeira Região -, foram aduzidas diversas controvérsias que se concatenam com as abordagens anteriormente realizadas.

O órgão ministerial alega que a resolução do CFM é inconstitucional e ilegal por ser decorrente de extrapolação dos limites de competência de uma entidade de classe, sendo verdadeira legislação editada por via indevida. Além disso, foram arguidos vícios materiais que fragilizavam a eficácia da regulamentação, pois havia diversas omissões e impropriedades quanto à forma de registro das diretivas ${ }^{16}$.

O Conselho Federal de Medicina contrapôs essas alegações afirmando que houve apenas o exercício da competência de cuidar do exercício dos profissionais de medicina, não havendo escopo de inovação jurídica, mas apenas de orientar a atuação médica e salvaguardar a autonomia individual e a dignidade do paciente (BRASIL, 2014, p. 182-203). Em relação às omissões, defendeu que elas não subsistem, uma vez que quaisquer pendências respectivas a isso são resolvidas pelo Direito Civil, o qual cuida das questões referentes à capacidade e as atinentes a negócios jurídicos (BRASIL, 2014, p. 194-198). E não há impropriedade no registro já que a utilização do prontuário como meio de registro não restringe a liberdade das formas, mas apenas e tão somente ressalta a sua importância como canal de comunicação principal entre o estado do paciente e o médico, não afetando sua natureza sigilosa, além do fato do assunto debatido nos autos já ser regulamentado em diversos países estrangeiros (BRASIL, 2014, p. 200-205).

Ambas as partes evidenciaram questões centrais ao instituto, as quais tocam até mesmo a própria adequação daquele enfrentamento inicial do tema feito administrativamente. Sobretudo, o que, de fato, observa-se é a resolução por meio do Judiciário de controvérsias possíveis de serem levantadas e que, em tese, fragilizam a regulamentação já havida para as diretivas.

O juiz de primeira instância iniciou sua apreciação ressaltando o seguinte. A omissão legislativa permite a expansão da vontade individual por meio das diretivas, não havendo, inclusive, extrapolação de competências. E isso porque o Conselho de Medicina - por

\footnotetext{
${ }^{16}$ Atinentes a requisitos pessoais dos pacientes, prazo de suas disposições, meios de revogação, critérios de participação de familiares e instrumento específico para o registro de vontade do paciente (BRASIL, 2014, p. 319). 
disciplinar temáticas conexas ao exercício profissional médico - edita normativos, orientando e impondo sanções aos seus administrados (BRASIL, 2014, p. 238).

Indo além, foi aduzido que as diretivas não trazem os vícios de omissão arguidos pelo Ministério Público, sendo compatível e complementada pelas normas constitucionais e legais de Direito Civil, respeitando, inclusive, o princípio de liberdade das formas, além de não contrapor a figura da família como elemento de consolidação da vontade da pessoa e de sua proteção (BRASIL, 2014, p. 238-240). Com base no exposto, julgou improcedente a ação, sendo interposto recurso pelo órgão ministerial que aguarda desfecho na segunda instância.

Conforme se observa, por meio da discussão judicial ora apresentada, a temática ultrapassou aquele momento incipiente de mera produção normativa administrativa, de vinculação incerta. A partir desse referendo judicial, passou a ser norma concreta e aplicável de orientação e informação não apenas acerca de instituto, mas também sobre elementos que o compõem interna (dispositivos de regulamentação) e externamente (aplicação normativa de vertente complementar a outras normas do sistema jurídico brasileiro).

Aprofundaram-se questões materiais e formais, resultando em elucidações acerca da adequação e admissibilidade da Diretivas Antecipadas de Vontade junto ao direito do Brasil. Por meio da decisão judicial relatada, constatou-se a explicitação do vácuo legislativo, a impossibilidade de inviabilizar direitos de cunho existencial no âmbito civilista sob o pretexto de inexistir norma regulamentadora e a prerrogativa dos órgãos de classe de exercer sua competência para defender os interesses envolvidos em problemáticas recorrentes no cotidiano de seus administrados.

Isso evidencia, sobretudo, proteção à autonomia volitiva como elemento primordial, coadunando não apenas, na seara do Direito Civil, com os princípios da teoria dos negócios jurídicos, mas também com o padrão ético social objetivado pela ciência médica contemporânea, o qual é alinhado aos ditames constitucionais de proteção à dignidade humana.

Assim é que a investigação realizada permite não apenas demonstrar o tratamento atual da temática ora analisada, mas também o avanço e enfretamento sobre questões que antes fragilizavam o próprio instituto. Porém, não somente avanços, desenvolvimento e características agregadoras ao direito brasileiro fazem parte do ideário teórico do tema, há também retrocessos e óbices a ela, consoante será demonstrado a seguir. 


\section{4 ÓBICES E RETROCESSOS EM FACE DAS DIRETIVAS ANTECIPADAS NO BRASIL}

As Diretivas Antecipadas de Vontade não apresentam somente marcos crescentes de avanço em sua eficácia, regulamentação e aplicação na realidade social. A temática sofre óbices e retrocessos diversos, os quais devem ser abordados a fim de se atender o escopo das possibilidades desse instituto na realidade jurídica do Brasil. E isso será realizado não apenas com contrapontos ao que já foi demonstrado.

O primeiro óbice que afeta negativamente a construção teórica das Diretivas Antecipadas de Vontade é a inexistência de um referencial legislativo que a informe como norma de possibilidade. Como se viu nos consideranda e justificativas da Resolução 1.995/2012, é impreterível um regramento em forma de lei em sentido estrito, não apenas porque o País detém tradição e cultura jurídica de primazia à norma legiferada, mas também em razão de os indivíduos participantes de um contexto da relação médico-paciente necessitarem de um padrão de conduta geral.

Outro óbice decorre da própria Resolução 1.995/2012. É que a regulamentação por ela disposta é incoerente com a própria estruturação teórica das Diretivas Antecipadas de Vontade. E isso porque aquele regramento administrativo não foi elaborado com vistas ao fato de que as Diretivas Antecipadas de Vontade são um gênero do qual decorrem diversas espécies (THOMPSON, 2015, p. 868).

Além disso, existe confusão conceitual disso resultante, posto que há utilização de diretivas como sinônimo de testamento vital - living will - e como conceito diverso do mandato duradouro para terceiros. Em verdade, ambos são negócios jurídicos existenciais e espécies de diretivas que podem coexistir - não excludentes -, que se diferenciam pelo elemento subjetivo referente à forma de comunicação da vontade do indivíduo impossibilitado de fazê-lo.

Ademais, diante da constatação de que os aportes teóricos das diretivas se sofisticaram, desvinculando-se a situação de terminalidade vital como elemento primário em razão do surgimento de novas modalidades de manifestações prévias ${ }^{17}$, a estrutura conceitual não demanda essa situação de fim de funções biológicas. Isso amplia as possibilidades e reforça a centralidade da autonomia volitiva.

\footnotetext{
${ }^{17}$ Reitere-se: Advance Medical Care Directive; value history; a Combine Directive; e o Physician Orders for Life-Sustaining Treatment (POLST). 
Assim, o regramento existente expedido pelo Conselho Federal de Medicina é problemático e representa um revés - ou melhor, é contrário - à configuração teórica da temática. E isso porque, em suma, trata-a aquém do que o necessário e, quando o faz, realiza-a de forma oposta ao que realmente deveria fazer, trabalhando contra uma compreensão correta do assunto.

A situação ainda se agrava quando se afere que esse é o único referencial normativo mais próximo das partes em situação de alta fragilidade, o qual é o contexto de encerramento das funções vitais. $\mathrm{O}$ que se pretende com essa constatação não é retirar os méritos da norma administrativa como orientação deontológica e avanço na proteção da autonomia volitiva e do exercício digno do Direito à Vida. E sim evidenciar que é - pelo que se retratou como primeiro ponto de inflexão - necessário um vetor decorrente de um processo legislativo. Porém, até mesmo esse norte de condutas deve ser originado no contexto hodierno da matéria, aplicando-se, ainda, a legislação civil comum relativa aos atos jurídicos em sentido amplo e de negócios jurídicos.

Ao lado disso, em 2019, foi editada a Resolução n ${ }^{\circ}$ 2.232, de 17 de julho de 2019, pelo CFM, a qual complementa a Resolução 1.995/2012, estabelecendo normas éticas para recusa terapêutica por pacientes e objeção de consciência na relação médico-paciente.

E, embora represente - à primeira vista - um reforço específico às normas administrativas, ela aprofunda e tornam mais complexos os defeitos existentes no regramento primevo, pois parte dela como pressuposto válido. Todavia, conforme relatado, ela detém diversas incongruências com a teoria sedimentada do instituto.

Há quatro fatores principais que isso explicitam. O primeiro é o de que não há revisão dos conceitos utilizados, muito menos previsões de outras modalidades de diretivas além daquelas correspondentes ao mandato duradouro e o testamento vital - a serem empregadas ou aceitas pelos médicos.

O segundo decorre da verificação de que essa Resolução busca salvaguardar o médico ao desconsiderar os desígnios prévios do indivíduo, sem quaisquer critérios minimamente objetivos para tanto. Isso resulta - mesmo que em medida mínima e abstrata em mitigação da autonomia volitiva e impossibilidade de imposição de sanções ou persecução de reparação moral ou material (NUNES, 2016, p. 67), já que a objeção de consciência é irrestrita. 
De fato, ela é conceituação genérica e ampla que alberga uma miríade de situações, todas as quais - não importando a gravidade do dano perpetrado em face da personalidade do enfermo - podem ser transformadas em favor do profissional de medicina a despeito da deliberação do paciente quando de sua simples alegação.

Em outras palavras, cria uma zona de segurança por meio de um argumento que sobrepõe qualquer ato lesivo de desrespeito à vontade individual. E, sendo questão de cunho fortemente subjetivo, nem mesmo sua veracidade, idoneidade ou legitimidade podem ser aferíveis pelos meios comuns da prática jurídica contemporânea. Contudo, o que se evidencia aqui não é a extinção dela - pois também representa um direito de projeção constitucional do médico -, mas sim um maior controle e previsibilidade em situações às quais pode a objeção de consciência se configurar ou ser analisada, mesmo que minimamente.

O terceiro é a ocorrência de contradição - que toca o que foi por último exposto existente entre a realidade fática a que busca disciplinar e os efeitos das previsões normativas. É que - ao passo em que em seus consideranda e em suas justificativas, essa resolução mais recente proclame respeito à dignidade e autonomia dos pacientes, elevando-o à posição de protagonista - as normas por ela veiculadas evidenciam intervenção do médico a seu próprio Juízo, independente da vontade particular. Desprestigia, assim, a vontade externada e o próprio ato jurídico por ela originado.

Isso representa implicação e retrocesso ao modelo paternalista de relação médicopaciente, em que o enfoque se encontra na autoridade médica e não no exercício efetivo da autonomia volitiva pelo paciente (CERQUEIRA, 2019, p. 13-14).

Como consequência, o que se observa é um mecanismo de proteção criado para a proteção do profissional médico, apesar de haver previsões que objetivem compatibilização com as normas diversas, o que é o caso dos dispositivos tocantes aos incapazes civilmente e às pessoas portadoras de deficiência. Entretanto, isso se apresenta como contradição ao que foi estabelecido como parâmetro de complementariedade dos âmbitos jurídico e administrativo na Ação Civil Pública já investigada. É que dispensável, como foi defendido pelo órgão público, o tratamento de questões de capacidade e discernimento, quando a legislação específica já o faz (BRASIL, 2014, p. 194-198; 238-240). Todavia, isso não é o que se observou nessa nova resolução.

Embora seja o de menor relevância, o quarto fator decorre de elencar novas possibilidades de registro, o que evidencia fator problemático para discussões paralelas acerca CONPEDI LAW REVIEW | EVENTO VIRTUAL | v. 7 | n. 1 | p. 110 - 130 | JAN - JUN | 2021 
de usurpação de competências, consoante já ocorrido judicialmente. Com efeito, a maior complexificação de atos registrais para a estruturação do ato vai contra a argumentação, inclusive, explicitada em sede dos autos do processo acima perquirido, concernente a não haver qualquer objetivo de instituir formas de validade negocial por meio dessas orientações.

Primordialmente, uma maior simplicidade de registro dá ensejo à ideia de respeito à liberdade das formas, bem como é a ela compatível. No entanto, a concretização dessa harmonia entre o sistema administrativo e o sistema legislativo se vê afetada quando a complexidade prevista é ressaltada naquela em detrimento deste.

Diante do exposto, em última instância, conclui-se que a referida resolução se apresenta, sob o pretexto de avançar na proteção da autonomia volitiva, como ponto de inflexão que retrocede o desenvolvimento alcançado pelo pioneirismo inicial do CFM.

Junto aos que já se perquiriu, há mais um obstáculo às Diretivas de Vontade no direito brasileiro. Ele resulta daquela ação civil pública que trata da temática e ainda se encontra em tramitação junto à segunda instância do Judiciário Federal, no Tribunal Regional Federal da $1^{\text {a }}$ Região. Efetivamente - mesmo que, por um lado, ela represente avanço na instituição, inserção das Diretivas Antecipadas no Direito brasileiro e admissão do ato negocial por ela originado -, há uma vertente dela que pode ser constatada como entrave. É que houve redução do tratamento da questão à análise da temática no âmbito da deontologia (BRASIL, 2014, p. 238-240). Todavia, ela é mais ampla que isso, especialmente em função da necessidade de exercício de um direito em função da omissão legislativa. E isso principalmente no âmbito da autonomia da vontade.

Já se observou, entretanto, que há cunho além do plano das normas de atuação profissional, motivo pelo qual deve ser tratado para garantir continuidade no desenvolvimento das perspectivas de regramento jurídico por parte do Judiciário, aprofundando a temática. Atribui-se esse revés ao fato de que o processo ainda se encontra - apesar de ser ação representativa do tema atinente ao interesse social, intrínseco à própria concepção de Ação Civil Pública - em fase incipiente de tramitação, detendo ainda possibilidade de adentrar outras esferas temáticas além da deontologia. Inclusive, nesse mesmo contexto, visto que intensificado - no resultado da ação - o foco da discussão do assunto àquela seara extrajudicial, ainda sim é um início para discussão sobre a sua influência em outras searas.

Com base no exposto, é possível observar que a matéria das Diretivas Antecipadas de Vontade se encontra em discussão, desenvolvimento e aprofundamento na realidade 
jurídica brasileira. E, conquanto haja avanços reiterados sobre essa matéria, existem óbices de natureza diversas, mas conexas à fase assimilação do instituto no País.

Isto, em algumas perspectivas, pode resultar em retrocessos pontuais, decorrentes de mudanças de foco do escopo jurídico que se quer prestigiar. No entanto, todos os avanços, estagnações, retrocessos e óbices são válidos para delinear as possibilidades do instituto no direito nacional.

\section{CONSIDERAÇÕES FINAIS}

Ante tudo quanto exposto, observa-se que as Diretivas Antecipadas de Vontade detêm possibilidades de garantir uma nova medida de prestígio à autonomia volitiva, ao exercício do direito à vida e à dignidade humana. Elas têm como escopo a conformação da conduta de profissional de medicina por meio de manifestações prévias de vontade do paciente acerca de tratamentos médicos para situações em que o elemento volitivo não seja possível de ser externado.

A sua configuração teórica se encontra compatível com os ditames atuais do Direito Civil brasileiro, especialmente no que tange à teoria dos atos jurídico, com foco ao que se admite para os negócios jurídicos e para as categorias decorrentes deste. Assim, produz efeitos e resultados colimados pelos seus integrantes.

Por produzirem seus efeitos em âmbito entre particulares, a inexistência de legislação específica que a conforme não é obrigatória, sendo dispensável, em que pese lhe seja aplicável a legislação civil comum. Porém, é considerada como uma adição conveniente em função de inseguranças dos indivíduos não familiarizados com o plano jurídico e, mormente, dos entraves originados por meios subjetivos constituídos para mitigar as prerrogativas da pessoa. Isto é o que se observa das normas originadas pela Resolução 2.232/2019 do Conselho Federal de Medicina (CFM).

Aliás, um regramento legislativo é necessário como forma de erigir um referencial melhor e mais adequado à configuração teórica já existente para as diretivas. É que, conforme analisado no decorrer deste texto, o regramento instituído a partir da Resolução 1.995/2012 do mesmo CFM é incongruente com a temática, trazendo confusão e imprecisões conceituais. $\mathrm{O}$ que se agrava com o advento daquela resolução mais recente.

A admissibilidade desse instituto se faz necessário tanto por um imperativo de adequação e harmonia internacional quanto com o estado da arte da ciência médica e dos 
influxos da dignidade como novo parâmetro ético. E também porque já referendado judicialmente, mesmo que em segundo plano, pois não foi o escopo primordial do desfecho processual da Ação Civil Pública nº 0001039-86.2013.4.01.3500.

Sua delimitação se estende ao cunho existência do próprio indivíduo e seu objetivo é efetivar a sua vontade consigo, devendo ser respeitada, como é efetivado para os atos negociais comuns. E ela encontra conformação na autonomia individual aliada ao exercício pleno da Dignidade Humana em conjunto com o Direito à Vida e à integridade da personalidade.

Ante esse panorama, as diretivas são admissíveis em nossa ordem jurídica e tornam possível o integral exercício dos desígnios individuais a partir de ato negocial de conteúdo existencial no contexto da relação médico-paciente. Elas objetivam a existência plena da pessoa até mesmo em situações de fragilidade e de impossibilidade de expressão de sua vontade, protegendo a sua personalidade e viabilizando o propósito por ela colimado.

Isso representa mais do que um ganho de recursos jurídicos, inclusive para a constatação de condutas lesivas, de modo comissivo ou omissivo, aptas a ensejar o dever de indenizar, para a personalidade e os direitos dela projetados e para o conteúdo dos veiculado em atos negociais. Representa também um ganho humano à medida que, conforme dados demonstrados no decorrer do presente estudo, atende a anseios, preocupações, esperanças e intenções de pessoas em situações de intensa fragilidade.

\section{REFERÊNCIAS}

BEAUCHAMP, T. L.; CHILDRESS, J. F. Princípios da ética biomédica. $2^{\mathrm{a}}$ ed. São Paulo: Loyola, 2011.

BRASIL. Tribunal Regional Federal da $1^{\mathrm{a}}$ Região. Processo $\mathbf{n}^{0}$ 0001039-86.2013.4.01.3500, Ministério Público Federal e Conselho Federal de Medicina, 25 jan. 2014.

CAIXETA, Gabriel Ricardo Jardim. Silêncio legislativo, liberdade para legislar e omissão constitucional. 2015. Dissertação (Mestrado em Direito) - Faculdade de Direito, Universidade de São Paulo, São Paulo, 2016.

CERQUEIRA, Maria Clara Peleteiro. O direito de recusa a tratamento médico: os efeitos de uma análise ponderada entre o artigo 15 do Código Civil e o do 146, §3, I do Código Penal. Monografia (Graduação em Direito). Programa de Graduação em Direito, Universidade Católica do Salvador, Salvador, 2019. 
CONSELHO FEDERAL DE MEDICINA. Resolução CFM nº 1.995/2012. Dispõe sobre as diretivas antecipadas de vontade dos pacientes. Diário Oficial da União, Brasília, DF, 3 set. 2012.

CONSELHO FEDERAL DE MEDICINA. Resolução CFM nº 2.232/2019. Estabelece normas éticas para a recusa terapêutica por pacientes e objeção de consciência na relação médicopaciente. Diário Oficial da União, Brasília, DF, 16 set. 2019.

DADALTO, Luciana. Diretivas Antecipadas de Vontade: proposta de modelo brasileiro. Tese (Doutorado em Medicina). Programa de Pós-Graduação em Infectologia e Medicina Tropical, Universidade Federal de Minas Gerais, Belo Horizonte, 2013a.

DADALTO, Luciana. Testamento vital. 2. Ed. Rio de Janeiro: Lumen Juris, 2013b.

DADALTO, Luciana; TUPINAMBÁS, Unai; BARTOLOMEU, Dirceu. Diretivas Antecipadas de Vontade: Um modelo brasileiro. Revista Bioética - CFM. v. 21, n.3, p. 463 476, 2013.

EMANUEL, E. J.; EMANUEL, L. L. Living wills: past, present, and future. J Clin Ethics, v. 1, n. 1, p. 9-19, 1990.

GRAU, Eros Roberto. A constituinte e a constituição que teremos. São Paulo: Revista dos Tribunais, 1995.

JOHN, E.; HEFFNER, J. E.; BARBIERI, C. End-of-life care preferences of patients enrolled in cardiovascular rehabilitation programs. Chest Journal, v. 117, n. 5, Illinois, p. 1474-1479, 2000 .

KUTNER, Luis. Due process of euthanasia: the living will, a proposal. Indiana Law Journal, v. 44, n. 4, p. 539 - 554, 1969.

LIMA, Caroline Melchiades S. G. de S.; SANTOS, Pedro Henrique A. F. dos; MARQUESI, Roberto Wagner. Negócios jurídicos contemporâneos: a efetivação da dignidade da pessoa humana com alicerce nos contratos existenciais. Revista civilistica.com, v. 7, n. 3, p. 1-24, 2018.

LOPES, Antônio Carlos; LIMA, Carolina Alves de Souza; SANTORO, Luciano de Freitas. Eutanásia, ortotanásia e distanásia: aspectos médicos e jurídicos. 2 Ed. São Paulo: Atheneu, 2014.

MABTUM, Matheus Massaro; MARCHETTO, Patrícia Borba. O debate bioético e jurídico sobre as diretivas antecipadas de vontade. São Paulo: Cultura Acadêmica, 2015. 
MAYORAL, Vânia Ferreira de Sá. Adaptação transcultural do formulário POLST: Physician Orders for Life-Sustaining Treatment. 2016. Dissertação (mestrado em Saúde Coletiva) - Faculdade de Medicina, Universidade Estadual Paulista, Botucatu, 2016.

MENDES, Gilmar. Jurisdição constitucional: o controle abstrato de normas no Brasil e na Alemanha. São Paulo: Saraiva, 1999.

MONTEIRO, Renata da Silva Fontes; JÚNIOR, Aluísio Gomes da Silva. Diretivas Antecipadas de Vontade: percurso histórico na América latina. Revista Bioética - CFM. v. 27, n.1, p. $86-97,2019$, p. 87.

NUNES, Rui. Diretivas antecipadas de vontade. Brasília: CFM / Faculdade de Medicina da Universidade do Porto-Portugal, 2016.

PENALVA, Luciana Dadalto. As contribuições da experiência estrangeira para o debate acerca da legitimidade do testamento vital no ordenamento jurídico brasileiro. In: CONGRESSO NACIONAL DO CONPEDI, 17, 2008, Brasília. Anais. Brasília, DF: Conpedi, 2008, p. 516-538.

PICCINI, Cleiton Francisco et al. Testamento Vital na perspectiva de médicos, advogados e estudantes. Bioethikos, v. 5, n. 4, p. 384-391, 2011.

PITELLI, Sergio Domingos. O poder normativo do Conselho Federal de Medicina e o direito constitucional à saúde. Revista de Direito Sanitário. v. 3, n. 1, mar., p. 38-59, 2002.

PONA, Éverton Willian. Testamento vital e autonomia privada: fundamentos das diretivas antecipadas de vontade. Curitiba: Juruá, 2015.

SAHM, S.; WILL, R.; HOMMEL, G. What are cancer patients' pre-ferences about treatment at the end of life, and who should start talking about it? A comparison with healthy people and medical staff. Support Care Cancer, v. 13, n. 4, p. 206-214, 2005

SIMÓN-LORDA, Pablo; TAMAYO-VELÁZQUEZ, Maria-Isabel; BARRIO-CANTALEJO, Inés-Maria. Advance directives in Spain. Perspectives from a medical bioethicist approach. Bioethics, v. 22, n. 6, p. 346-354, 2008.

SILVA, Roberto Baptista Dias da. Uma visão constitucional da eutanásia. 2007. Tese (Doutorado em Direito) - Pontifícia Universidade Católica de São Paulo, São Paulo, 2007.

THOMPSON, Amy E. Advance Directives. Journal of the American Medical Association, v. 313 , n. 8, p. 868, 2015. 